\title{
Paisagens marginais e o percurso transgressor de Lúcio Cardoso
}

\author{
Odirlei Costa dos Santos \\ Universidade Federal de Juiz de Fora
}

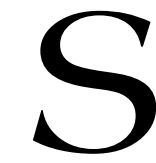

e nas províncias mineiras Lúcio Cardoso exploraria toda a claustrofobia ontológica de personagens calcinadas pelos desvarios da clausura interior, nas narrativas urbanas o autor romperia as barricadas excessivas da introspecção, face à sua imagerie expressionista de formas, cores e imagens. Em uma de suas últimas viagens pelo interior de Minas Gerais, de passagem pela cidade de Ubá, zona da mata mineira (onde possivelmente, pelos seus arredores, poderia ser encontrada a decaída mansão dos Meneses de Crônica da casa assassinada), Lúcio explicitaria suas mais pungentes e definitivas impressōes sobre o estado. Seria pelo registro diário que confirmaria a latência do seu ódio e de sua fascinação por Minas, "esse espinho que não consigo arrancar do meu coração." "Todos esses ambientes sombrios de seus livros e novelas parecem se remeter a uma eterna "tristeza mineira" que tanto o perseguiu e o fazia lastimar: "Minas é muda e cega. Sua crueldade vem do sentimento terrível do seu poder: são léguas e léguas de brejos, carrascais, lama, poeira e desolação."2 Minas Gerais e suas longas estradas empoeiradas e soturnas, suas fazendas outrora faustuosas a ostentar a derrocada dos valores e tradições mineiros, suas residências misteriosas de portas e janelas sempre cerradas - Mario Carelli lembraria, em Corcel de fogo, que a casa da fazenda Cata-ventos, de $O$ desconhecido, lembraria o palácio de Nosferato do cineasta Murnau -, suas personagens carregadas de um ódio tão perene quanto amargamente silencioso definiriam os contornos e matizes do universo

${ }^{1}$ CARDOSO, 1970, p. 293.

${ }^{2}$ CARDOSO, 1970, p. 293. 
cardosiano e de todo o fomento de sua literatura de introspecção, o que colocaria Lúcio em definitivo como "um inventor de totalidades existenciais", ${ }^{3}$ segundo Alfredo Bosi em História concisa da literatura brasileira. Na novela $O$ desconhecido, a personagem homônima se encontra perdida em meio ao completo abandono da estrada antes de chegar à fazenda Cata-ventos, e a descrição da paisagem mineira a beirar o fantástico mostra como o olhar de Lúcio para a província estava prenhe de sensações mórbidas e premonições obscuras e intricadas. Interessante notarmos como o fragmento se esboça como espécie de establishing shot cinematográfico, tal a visualidade de ícones típicos dos soturnos rincões mineiros, como o ocaso da luz, a cruz opressivamente posicionada, a poeira como o sucedâneo de um fog fantasmático:

Anoitecia. A sombra roxa do crepúsculo invadia toda a paisagem. Não sabia por que a impressão de isolamento se fazia maior; era como se aquela estrada conduzisse a um território proibido; mesmo a vegetação se tornava diferente, as árvores raras eram altas e desfolhadas, o capim incolor. O homem continuava a caminhar, o coração opresso. Uma cruz plantada à beira da estrada obrigou-o a se deter um minuto, os olhos baixos. Um assassinato, sem dúvida, desses tão comuns às cidades do interior. Nesse momento, erguendo a cabeça, avistou no fundo da estrada uma nuvem de poeira, uma enorme nuvem que parecia aumentar e se aproximar. Fixou a vista, julgou distinguir um carro. De novo assaltou-o uma emoção desconhecida, uma obscura angústia; tudo ali adquiria um aspecto sobrenatural, e aquele carro, rolando dentro da sombra roxa do crepúsculo, não fugia ao sortilégio que embebia as coisas. ${ }^{4}$

Não obstante, no ciclo das novelas urbanas, como Inácio, O enfeitiçado e Baltazar, encontramos o desenvolvimento de novas nuances de escrita e de novas possibilidades para a configuração de ambientes e tessituras existenciais. O espaço citadino seria o local propício para que Lúcio trabalhasse a exterioridade, onde a paisagem humana e dramática se projetaria sob outra perspectiva. A tríade de "Um mundo sem Deus" permitiria a Lúcio expor o excesso e o transbordamento dos estados de alma de suas personagens, mantendo a

\footnotetext{
${ }^{3}$ BOSI, [s/d.], p. 466.

${ }^{4}$ CARDOSO, 2000, p. 16.
} 
mesma postura emblemática de criador de totalidades existenciais, como afirmou Bosi. Tal excesso iria ajudar a compor seu ideário provocador e transgressor, ao carregar com violência cromática sua galeria repleta de tipos marginais e amorais, muitos deles beirando o exagero, o que não impediria de aproximá-los do kitsch e do grotesco. Em tais novelas urbanas Lúcio mostraria sua faceta ainda mais cáustica e demoníaca, já sem os alicerces mineiros para sustentar seus conflitos morais e espirituais, e o afã pela destruição se daria menos com a tortura ontológica encarcerada de suas personagens do que com o riso demoníaco escancarado dos transgressores morais. Embora a expiação moral e espiritual fosse sempre explorada ad nauseum por Lúcio, havia algo neste inferno que provocava a deformação das formas convencionais de encarar o sujeito burguês e citadino, o homem pseudocivilizado que vai de encontro às verdades negadas e sublimadas.

As novelas urbanas de Lúcio estão circunscritas a entrechos que optam por um completo desregramento de pensamentos e açôes, de tal forma que as personagens talvez sejam as mais bizarras e tresloucadas da trajetória cardosiana de escrita. A sondagem existencial percorreria os desvãos do basfond, com seus venenos lisérgicos e licenciosos, e desceria cada vez mais aos infernos das cidades, com seus drogados, "viciados" (espécie de eufemismo de Lúcio para os pederastas) e prostitutas decaídas, em espaços onde a transgressão se confunde à decadência. Os traços de suas personagens amorais seriam quase deliberadamente caricaturais, verdadeiras pantomimas grotescas de um teatro de horrores. Mesmo sem trabalhar diretamente com a paisagem urbana em sua prosa de ficção posterior a $O$ enfeitiçado (considerando que Baltazar foi publicada pos-mortem), as personagens citadinas, como Nina de Crônica da casa assassinada, ou Rafael (ou, no original que seria publicado, Kelene) de $O$ viajante, trariam em si as marcas da transgressão que deixariam todo o rastro de destruição pelas províncias mineiras. Nas primeiras anotações que Inácio Palma realiza em ritmo de confissão, em $O$ enfeitiçado, ${ }^{5}$ a paisagem instiga a possibilidade de rechaçar as primeiras cordas íntimas que sustentam a interiorização:

Quem nunca terá vivido como eu, olhando a paisagem prenhe de um acontecimento que não se decide, quem não terá vivido à espera de

\footnotetext{
${ }^{5}$ A referência à novela $O$ enfeitiçado será dada pela sigla $E$, seguida do número da página.
} 
alguma coisa, o sem-nome, o que de inesperado costuma acontecer na vida, o sobressalto, a pressão nessa pequena mola que aciona o destino e transforma os hábitos? (...) Sim, ousemos tudo. Já agora não há nenhum motivo para me deter a meio caminho. Que eu faça destilar aqui, ao meu possível leitor futuro, amigo e possivelmente semelhante, tudo o que nunca disse, o que sempre vivi, áspera e violentamente, contra tudo e contra todos, sozinho no meu desespero. Nessa semi-obscuridade, sinto o meu riso crescer como se viesse de longe... (E, p. 152-153)

Os ambientes citadinos compõem o espaço das pretensões de Inácio em busca dos seus últimos anseios, além de sinalizar o modo como toda a narrativa trágica se faria acompanhar pelo mesmo pensamento sardônico que seria o legado maior deixado ao seu rebento Rogério. Além da tão decantada vocação das personagens cardosianas para o Mal, a sugestão febril dos acontecimentos e o dínamo incessante a conduzir o ritmo das ruas e pessoas acirram o espírito a outras margens de perscrutação ontológica: "Ainda que estejamos acordados, ainda mesmo que protestemos e vivamos depressa (...) alguma coisa flui, escorre incessantemente na obscuridade, deteriora-se, alguma coisa que é nossa, particular e vital, infinitamente particular e desgraçadamente vital" ( $E$, p. 154-155). Inácio, espécie de dândi caricato em estágio último de derrocada moral, perambula por Lapa, Centro, Gamboa, Saúde, Meyer em busca de Rogério, além de percorrer os considerados antros mal freqüentados da cidade, hotéis suspeitos como Progresso do Meyer, Hotel da Lanterna e A Pastora de Nápoles. O território urbano é visto com terror e fascinação já que, como lembra Teresa de Almeida no ensaio "A metrópole expressionista", ao apontar o livro De Caligari a Hitler, o ensaísta Siegfried Kracauer "parece nos remeter a algumas das narrativas de Lúcio Cardoso, nas quais a representação da metrópole se mostra caracterizada em determinadas cenas por uma espécie de agressividade e desordem nela reinante, que porém tanto fascina seus protagonistas." ${ }^{6}$ Lúcio procura sublinhar a atmosfera soturna e enigmática das cidades sob o olhar do sujeito noturno, espécie de fascinação noir a acentuar sua estética expressionista:

...era tarde, era quase noite, ou melhor, era precisamente essa hora que eu tanto amo, hora em que as ruas escurecem e as luzes se

${ }^{6}$ ALMEIDA, 1998, p. 55. 
acendem. Nunca pude ficar em casa nesse momento. É preciso amar as cidades para adivinhar as horas em que palpita seu segredo mais fundo. É preciso ter os olhos bem abertos, os ouvidos à escuta, para perceber quando o mar se cala e a noite chega, com suas promessas e possibilidades. Ninguém saberá jamais o que é a noite para os noctívagos: eles se roçam nela, embriagam-se com sua cálida essência, resplandecem aos seus fogos concentrados. Desmesuradas, àquela hora as casas abrigavam a sombra. ( $E$, p. 156)

Lúcio urbano, a percorrer as ruas cariocas alternando estados de enfado e frenesi, se aproximaria do que Luiz Edmundo Bouças Coutinho chamaria de écrivain-dandy, em seu ensaio "Formas e truques de um écrivain-dandy". As próprias deambulações de Lúcio se confundiriam às projeçôes de suas escritas pessoais e ficcionais, como podemos observar no registro de seu Diário completo, ao passar pela Cinelândia ou pelo Café Vermelhinho: "Sinto que não é possível que tudo prossiga assim, nessa eterna espera, nessa angústia do nada e da mediocridade. No fundo do coração é a catástrofe que chamamos. Ninguém suporta a horrível monotonia da vida." ${ }^{8}$ Diante de seus projetos gorados para o cinema, Lúcio estabeleceria ainda mais pontos de confluência com a linguagem cinematográfica, como já vimos de antemão na citação de um fragmento de $O$ desconhecido. Ainda em seu Diário completo - que se iniciou justamente como "diário de bordo" do filme que tentou construir em 1949 -, Lúcio apontaria que "travellings, panoramas e long-shots nada mais são senão capítulos, frases, balbucios do mesmo romance que não se conclui nunca e que, através das imagens, procura apenas transmitir sua existência." Em outros trechos, seria o ainda adormecido pintor que daria contornos à violência cromática e a desvirtuação das formas com que olha o mundo exterior, como atesta em seu diário: "Há em mim, sem nenhuma dúvida, um artista plástico fracassado. Em certos momentos, tenho a impressão de que escrevo como se desenhasse." ${ }^{10}$ Aos poucos, Lúcio submete as paisagens urbanas ao seu olhar de cineasta e cenógrafo, para criar, mais do

${ }^{7}$ COUTINHO, 2004, p. 187-200.

${ }^{8}$ CARDOSO, 1970, p. 197.

${ }^{9}$ CARDOSO, 1970, p. 18.

${ }^{10}$ CARDOSO, 1970, p. 229. 
que meras descrições, intricadas sensações a partir de formas e matizes interiorizados - em seu diário lembra que "alguém, há tempos, achou esquisito que eu afirmasse não ser um escritor, e sim uma atmosfera" ${ }^{11}$-, que compõem a descrição de feiras de amostras, parques de diversões, festas populares com fogos, bandas de música, barracas e leilōes, multidões nos bares e nas portas dos cinemas e cafés, alternando a penumbra dos espaços obscuros e silenciosos com as cores berrantes e o rebuliço das pessoas da Lapa e do Centro, como afirma Rogério Palma em sua perambulação febril pelas ruas do Rio, na novela Inácio: "12 "detive-me à porta dos cinemas e sondei, por assim dizer, quase apaixonadamente, a multidão inquieta e faminta de prazeres (...) Quantos verão além da cama em que se deitam e procriam, quantos não seguirão a manada como bois submissos?" ( $I$, p. 23). A imagem da multidão em frente ao Outeiro da Glória, em meio aos devotos da santa, segue o mesmo viés descritivo em $O$ enfeitiçado: "Um rumor de rezas percorria a multidão ajoelhada, como um longo arrepio: por cima os foguetes rompiam o céu em duas trêmulas metades" ( $E$, p. 205). As luzes dos fogos, o rumor das gôndolas da roda gigante e o barulho distorcido das caixas de música parecem romper o marasmo de cores e sons da província, fazendo com que Lúcio consiga alternar as zonas de penumbra e sombra com o rasgo incontrolável de luzes, como o sol de Copacabana - algo poucas vezes observado na tessitura literária cardosiana, já que sua ambientação é quase sempre pouco afeita à luminosidade diurna -, sentido por Rogério ao lado do seu pai, quando estão ambos sentados em um bar: "Nossas melhores idéias, aquelas que acalentamos mais fundamente no âmago do ser, pelas quais vertemos nosso sangue e com que dilapidamos o melhor dos nossos sonhos, não se transformam, não ficam ridículas à luz de um sol tão forte, ante aquele mar que parece encerrar toda a alegria do mundo?” ( $I$, p. 111). Não obstante, as luzes e sons dissonantes dos parques de diversões, das feiras e dos espaços rumorosos vão aos poucos sendo substituídos pela surdina dos ambientes lúgubres e penumbrosos das ruas suburbanas: "Percorri ruas iluminadas e vielas escuras, atravessei linhas da estrada de ferro, detive-me sob pontilhões e viadutos, contemplando esse triste rebotalho humano que

\footnotetext{
${ }^{11}$ CARDOSO, 1970, p. 90.

${ }^{12} \mathrm{~A}$ referência à novela Inácio será dada pela siga I, seguida do número da página.
} 
fuma e se esconde sob as arcadas, à sombra das pilastras" (E, p. 217). O relato das impressōes nefastas atinge também as residências: "Cerradas, envoltas nas protetoras sombras da noite, pareceram-me absurdas vazias de sentido, monstros inertes aglomerados na escuridão" ( $E$, p. 227). Toda uma "vida secreta, pertinaz e dolorosa" ( $E$, p. 217) adensa os contornos de uma paisagem urbana soturna e abandonada por Deus, onde a loucura - essa eterna obsessão cardosiana - preenche os céus urbanos:

Edifícios, muralhas, casas, lojas, salas de assembléia, conselhos, fortalezas e prisões, erguiam-se formando um vasto mapa traçado pela ambição humana. E era impossível não sentir que um minúsculo elemento perturbava o andamento normal das coisas, que um pequeno órgão lacerado e triste, impotente na cegueira dos seus movimentos, palpitava sob os escombros daquele pesadelo. Surda, como uma vaga soterrada, a loucura viajava insone sob a laje dos edifícios. ( $E$, p. 218)

Se a atmosfera permanece carregada de signos obscuros, como nas novelas da província, o mistério da clausura de fazendas decadentes ou da sacristia de igrejas mineiras resvala para a penúria dos bares suspeitos e da zona de prostituição carioca desta cidade onírica. Temos cada vez mais a projeção de um Lúcio desregrado e boêmio, como se o autor aproveitasse suas próprias digressóes noturnas para deslindar a loucura e a derrocada moral de suas personagens citadinas. Cada vez mais atraído pelas paisagens marginais, a cidade permitiria a Lúcio ceder momentaneamente a seus impulsos transgressores, longe de sua eterna Minas Gerais introjetada:

Não sei, é claro, se são estes os caminhos em que deveria me arriscar, mas geralmente eu me arrisco em todos, sem me prender a nenhum. Tudo é perigoso, para quem sofre vertigens. Mas para quem não desdenha os grandes saltos na inquietação e no obscuro, tudo é bom para ser visto de perto. (Digo TUDO: as casas cheias de sombra e promessas aliciantes, os grandes becos da nevrose, o tóxico, os olhos insones do ciúme, as renúncias nas sacristias afastadas, os livros da magia, os claros escritórios do jogo e da ambição, o inimigo subterrâneo que nos saúda, a prostituta que nos recebe sem suspeita, a conversa que pode decidir o futuro, TUDO) (...) Decerto essas experiências nos envelhecem, quando a elas vamos sem nenhuma pureza de coração, quando as consideramos uma finalidade. Mas 
quando as aceitamos como uma simples possibilidade à nossa revelação, são elas, exatamente, que nos garantem a permanência do dom da mocidade. Elas é que nos conduzem perpetuamente a novas paisagens, que nos auxiliam a afugentar o espectro macio do sono, e nos desvendam implacavelmente os cimos mais raros do perigo. ${ }^{13}$

Em uma espécie de flânerie bem mais vertiginosa e febril, projetada pelos desvarios de Inácio e Rogério Palma, Lúcio encontraria possibilidade de expandir seu desregramento decadente e adensar ainda mais o estado de completo desvario, o que não o impediria de conduzir seus entrechos às raias da completa irrealidade e ilogicidade, como acusam muito de seus críticos e detratores literários. Estabeleceria também a partir disso uma intrincada relação entre a loucura e a letargia moralizante do homem moderno, como afirma o jovem Rogério, desperto em estado alucinatório do marasmo da vida regrada: "Adoeci de tanta mediocridade" ( $I$, p. 30). E completa: "Não acredita que se possa morrer de mediocridade? Pois morre-se. Os médicos é que dão nomes diferentes, mas estou convicto de que cada doença corresponde exatamente a um estado de pressão moral que muitas vezes é ignorada pelo próprio paciente" ( $I$, p. 30). Rogério parece acordar de uma espécie de torpor, ao errar pelas ruas da cidade em absoluto delírio, ciente de que "não há casas, nem ruas, nem homens, mas idéias, apenas idéias em ação, idéias que se matam, que amam e raciocinam, idéias que envelhecem de repente e outras que aos poucos vão não valendo mais nada (...) O que é preciso é ter sempre idéia mais forte" (I, p. 22). Este jovem monstro moral de 19 anos se reveste de força alucinatória para colocar seus planos em ação e encontrar seu pai, impondo uma imagem pessoal de metralhadora giratória sempre impiedosa: "O amor da humanidade, estou cuspindo em cima dele! Os homens, para mim são seres grotescos e miseráveis, acima de quem pretendo me colocar bem ostensivamente...” ( $I$, p. 28). Lúcio aproveita o ensejo do discurso de Rogério Palma para rechaçar as dissimuladas noções de bondade e altruísmo, estes eternos arremedos enfraquecidos da falta de viço para o $\mathrm{Mal}$ - o que faria Rogério Palma vociferar: "O mundo apodrece de caridade" (I, p. 29) -, como podemos observar a partir de Genealogia da moral (1887), de Friedrich Nietzsche:

\footnotetext{
${ }^{13}$ CARDOSO, 1970, p. 28-29.
} 
Se os oprimidos, pisoteados, ultrajados exortam uns aos outros, dizendo, com a vingativa astúcia da impotência: "sejamos outra coisa que não os maus, sejamos bons! E bom é todo aquele que não ultraja, que a ninguém fere, que não ataca, que não acerta contas, que remete a Deus a vingança, que se mantém na sombra como nós, que foge de toda maldade e exige pouco da vida, como nós, os pacientes, humildes, justos" - isto não significa, ouvido friamente e sem prevenção, nada mais que: "nós, fracos, somos realmente fracos; convém que não façamos nada para o qual não somos fortes o bastante; mas esta seca constatação, esta prudência primaríssima, que até os insetos possuem (os quais se fazem de mortos para não agir "demais", em caso de grande perigo), graças ao falseamento e à mentira para si mesmo, próprios da impotência, tomou a roupagem pomposa da virtude que cala, renuncia, espera, como se a fraqueza mesma dos fracos - isto é, seu ser, sua atividade, toda a sua inevitável, irremovível realidade - fosse um empreendimento voluntário, algo desejado, escolhido, um feito, um mérito." 14

Anos depois, Inácio continuaria a alimentar um pensamento sucedâneo diante da vida decomposta pela mediocridade e pelas misérias ditadas pela "má consciência", 15 quando afirma que "os coraçóes batem sem alma, um imenso véu de neblina e tédio se estende sobre o mundo. Mundo mofado, mundo de sono e odiosa quietude" (E, p. 171). E completaria que "esse tóxico que altera a paisagem inteira, aos poucos nos embrutece e nos transforma em rígidas estátuas de cor cinza, monstros de mofo e anestesia, cidadãos de um vasto reino onde prevalece a falta de energia e de finalidade" ( $E$, p. 171-172). O que permanece é um tipo de ódio latente e sem vigor, "um sentimento antigo e sem grandeza, um estado por assim dizer larvar a que nos submetemos, uma falta de graça, uma estilização do nada" ( $E$, p. 172). O tédio, a mediocridade, o excesso de altruísmo hipócrita que ascendeu no homem católico e moderno, em uma "tartufice dos mansos animais domésticos" ${ }^{16}$ remetem uma vez mais a Genealogia da moral:

\footnotetext{
${ }^{14}$ NIETZSCHE, 2006, p. 55.

${ }^{15}$ NIETZSCHE, 2006, p. 72.

${ }^{16}$ NIETZSCHE, 2006, p. 55.
} 
O ensombrecimento do céu acima do homem aumentou à medida que cresceu a vergonha do homem diante do homem. O olhar pessimista enfastiado, a desconfiança diante do enigma da vida, o gélido Não do nojo da vida - estas não são características das épocas de maior maldade do gênero humano: como plantas pantanosas que são, elas surgem apenas quando há o pântano que necessitam - refiro-me à moralização e ao amolecimento doentios, em virtude dos quais o bicho "homem" aprende afinal a se envergonhar de seus instintos. A caminho de tornarse "anjo" (para não usar palavra mais dura) o homem desenvolveu em si esse estômago arruinado e essa língua saburrenta, que lhe tornaram repulsivas a inocência e a alegria do animal, e sem sabor a própria vida - de modo que por vezes ele tapa o nariz diante de si mesmo, e juntamente com o papa Inocêncio III prepara, censura no olhar, o rol de suas repugnâncias ("concepção impura, nauseabunda nutrição no seio materno, ruindade da matéria de que se desenvolve, cheiro hediondo, secreção de escarro, urina e excremento"). ${ }^{17}$

Ao mergulhar nas paisagens marginais, Lúcio estabelece proximidade com o escritor Jean Genet (1910-1986), homossexual, ladrão e prostituto, do qual foi leitor e admirador, o que permite deslindar muitos pontos de convergência com os textos do escritor francês. O decadente que desafia a Deus e o incenso da sacristia pelas impressões do ultrajante Inácio Palma "criação de um Deus impotente para arrastar suas criaturas até a luz plena, ali jaziam os destroços de sua visão, consciências vivas e visionárias cerceadas de todos os lados pela doença, pela fome, pelo tédio, pelo vício e pela morte" (E, p. 227) - se aproxima do entendimento da vocação amoral do autor de Diário de um ladrão. Se o papa promulga a imundície que instiga o homem a envergonhar de si mesmo, os malditos, impuros e criminosos de Genet aparecem para reabrir as chagas diante da insipidez do homem domesticado:

Assim, por um grosseiro subterfúgio, eis que estou falando novamente dos mendigos e dos seus males. Atrás de um mal físico real ou fingido que o distingue e o faz esquecer, mais secreto um mal da alma se dissimula. Enumero as chagas secretas:

${ }^{17}$ NIETZSCHE, 2006, p. 56-57. 

Os dentes estragados,
O hálito fétido,
A mão cortada,
$\mathrm{O}$ fedor dos pés etc.

Para escondê-las e estimular o nosso orgulho, tínhamos:
A mão cortada,
O olho vazado,
A perna de pau etc.

Enquanto trazemos sobre nós as marcas da degradação, somos uns degradados, e mesmo que não nos abandone a consciência da impostura, isso de nada nos vale. Só quando utilizávamos o orgulho imposto pela miséria é que provocávamos a piedade cultivando as chagas mais nojentas. Nós nos tornávamos uma censura à felicidade de vocês. ${ }^{18}$

No Progresso do Méier, um dos bares freqüentados por Inácio, a personagem reconheceria "em cada um daqueles rostos isolados, todos eles exprimindo paixōes diferentes, o tédio, o ódio, a cobiça, a insatisfação, a carne, o orgulho, a fantasia e a vaidade.” (E, p. 178). Continua a circular pelos antros noturnos do Rio, "afrontando os olhares agressivos e as propostas sem pejo, a risada das mulheres fáceis e o trânsito angustiante desses corredores mal freqüentados" (E, p. 199). De algum modo, Lúcio pode exteriorizar modos de confundir a errância de Inácio pelo mundo marginal às possibilidades de um discurso livre do entendimento do que o homem considera justo e sensato: "Muitas vezes vi-me apenas como uma força bruta e sem destino, independente dos rigores das leis e dos sábios mandamentos instituídos como a base sacramental da sociedade" ( $E$, p. 215). Já em um estabelecimento com o curioso nome Hotel da Lanterna, Inácio encontra uma personagem que bem seria uma espécie de vingança pessoal do seu criador pelos tempos de sacristia mineira:

No fundo do corredor, por detrás de uma cortina esburacada, vejo surgir de repente uma figura impressionante: é um rosto chato, intensamente pálido, onde dois olhos miúdos, vivos, examinam tudo

${ }^{18}$ GENET, 1986, p. 52. 
com assustada curiosidade. Ao me ver, o homem que se achava evidentemente sentado, levanta-se, suspende a cortina - percebo então que se trata de um padre, que aos meus olhos atônitos ainda conserta a batina desalinhada e suja. Não há nenhum acanhamento nos seus gestos, antes me fita com insolência, ajeitando a roupa com calma, os dedos finos correndo ao longo das pregas que descem até o chão empoeirado. Em certo momento, como ele se voltasse em direção ao bureau do gerente, percebi que trazia na face esquerda uma enorme cicatriz, profunda e recente, um talho a navalha que lhe desfigurava completamente a expressão do rosto (...) Vi então, no fundo, num dos quartos menores, dois pés calçados de botinas pretas que ultrapassavam o foro ${ }^{19}$ de chita, pertencentes a alguém que se achava deitado, mas cujo tamanho insólito ultrapassava as medidas exíguas da dependência. Não duvidei de que se tratava novamente do padre, entregue às influências mágicas do tóxico. ( $E$, p. 222-223)

Além de sua intenção deliberadamente provocadora de ostentar o halo da santidade chafurdando no deleite dos vícios noturnos, notamos como as novelas cardosianas exploram o uso de tóxicos e do álcool como catalisadores do estado alucinatório - Mario Carelli lembraria, em Corcel de fogo, que "o olhar do alcoólatra sobre o mundo" ${ }^{20}$ seria uma das obsessões de Lúcio. O próprio Lúcio foi um consumidor contumaz de anfetaminas e de bebidas, como atesta sua irmã Maria Helena Cardoso em Vida vida (1973) e como expõe sutilmente o autor em alguns fragmentos de Diário completo. Neste último, Lúcio cita o contato com jovens rapazes (Lúcio não dispensava a companhia de mancebos desregrados) que rompiam ampolas de kelene (espécie de anestesiante homônimo ao do protagonista de $O$ viajante). Durante suas incursóes noturnas, Lúcio se impressionava como tais jovens burgueses "a isto se atirem com gritos de prazer e estremecimentos animais: como que da sombra alguma coisa mais primitiva e mais antiga do que o próprio homem, acorda em suas faces necrosadas o gosto do imundo." 21 Esta imagem dos rapazes - que, embora tenha um certo tom pseudomoralizante em seu

\footnotetext{
${ }^{19}$ Esta edição, utilizada pelo autor do ensaio, traz um erro de transcrição, aparece "foro" em vez de "forro", conforme lemos na primeira edição de 1954, p. 84. [Nota dos organizadores] ${ }^{20}$ CARELLI, 1988, p. 130.

${ }^{21}$ CARDOSO, 1970, p. 195.
} 
diário, causava intensos estados de fascinação no escritor - seria retomada durante a peregrinação de Inácio pelos subúrbios cariocas:

Às vezes, através do movimento e da agitação que reinava nessas sedes do vício, julgava distinguir uma fisionomia que me lembrava qualquer coisa - ao me aproximar, no entanto, verificava que se tratava apenas de um jovem da sua idade, pálido, sugado pelo prazer, pelo álcool e pelo esforço das noites alegres. Instintivamente comparava-os comigo mesmo - e tinha certeza de que não viveriam muito, pois entregavamse sem resguardo à alegria, num furor de quem visasse apenas a autodestruição (...) Não, esses jovens não se divertiam - consumiam apenas, em vastas horas de delírio e esquecimento, a tristeza de viver. Eram velhos sem esperança, restos humanos que haviam tombado cedo dos galhos sem seiva do conhecimento. (E, p. 200)

Lúcio não desconhece o comportamento típico dos "centros viciados da cidade", o que acirra ainda mais sua admiração pelo mundo marginal e pelos jovens criminosos do bas-fond, fazendo Lúcio-Inácio apreender "que miserável comédia representa a existência neste mundo, que sonho de escuridão e obscenidade é o caminho do homem sobre a terra" ( $E$, p. 167) e intensificar o desejo de devassa moral: "Não, nossa única obrigação é sermos fortes, intratáveis, selvagens na satisfação dos nossos desejos e fantasias" ( $E$, p. 167). Por mais que se refira a "uma profunda fraqueza" ligada a instintos de ordem sexual (principalmente o homoerotismo), a licenciosidade está plenamente relacionada aos modos de transgressão, fazendo com que Lúcio subscreva por linhas sinuosas sua atenção obsedante pelo castigo ditado aos sujeitos transgressores, sob forma de crime, sangue e violência. Expõe em seu Diário completo: "Esses homens, precisamente esses que vislumbro em meio à multidão, que parece não trazerem a alma nos olhos, mas ausência e frieza. É que, vagarosos, vão impelindo para frente a única identidade a que realmente dão importância, o sexo." E completa: "É como se carregassem um gigantesco sexo na alma." 22 Não obstante, a sexualidade transgressora compõe parte do jogo literário lúdico, das suas zonas de desvelamento e ocultação que alternam sombra e luz sobre esta sua "inquietação de felino". ${ }^{23}$ Lúcio joga o

\footnotetext{
${ }^{22}$ CARDOSO, 1970, p. 278-279.

${ }^{23}$ CARDOSO, 1970, p. 136.
} 
tempo todo com estas possibilidades de transgressão, como desvela na ambivalência/ambigüidade de sua própria imagem em Diário completo: "Estranho dom: Deus deu-me todos os sexos." ${ }^{24}$ Afirma ainda: "Nada renego da minha natureza, porque daquilo que me faz, de merda e sangue, construirme-ei definitivo e avaro." ${ }^{25}$ As possibilidades de transgressão do universo marginal esboçam novas referências a Genet em Diário de um ladrão: "Júpiter rapta Ganimedes e o viola: eu poderia ter-me permitido todas as devassidões. Possuía a elegância simples, a desenvoltura dos desesperados. A minha coragem consistiu em destruir todas as habituais razões de viver e em me descobrir outras." 26 A forma como oscila diante do crime e da violência apenas sublinha de algum modo seu fascínio desmedido pelo mundo marginal, como atesta uma vez mais em seu Diário completo: "Esta perpétua tendência à autodestruiçãa... Sim, de há muito ela existe em mim e eu a conheço como um doente acaba conhecendo o próprio mal. É incalculável o número de ciladas que invento para me perder." ${ }^{27} \mathrm{O}$ terror diante da loucura e da licenciosidade apenas intensifica o êxtase com que Lúcio se antepõe emocionalmente à sua vocação para os excessos, como lembra Bataille em $O$ erotismo:

Para ir até o fim do êxtase em cujo prazer nos perdemos, devemos sempre colocar o seu limite imediato: o horror. A dor dos outros, ou a minha própria, aproximando-me do momento em que o horror me atacará, pode me fazer chegar ao estado de felicidade próximo ao delírio, e também não há nenhuma forma de repugnância em que eu não veja a sua afinidade com o desejo. Não que o horror nunca se confunda com a atração, mas se esta não pode inibi-lo, destruí-lo, ele termina por reforçá-la. O perigo paralisa, mas se não for tão forte, pode excitar o desejo. Não alcançamos o êxtase, a não ser se ele não estivesse tão distante, na perspectiva da morte e do que nos destrói. ${ }^{28}$

\footnotetext{
${ }^{24}$ CARDOSO, 1970, p. 295.

${ }^{25}$ CARDOSO, 1970, p. 202-203.

${ }^{26}$ GENET, 1986, p. 167.

${ }^{27}$ CARDOSO, 1970, p. 30.

${ }^{28}$ BATAILLE, 1987, p. 248.
} 
Notamos como todo o percurso marginal pelas cidades compõe parte do arsenal de transgressões que viceja a intenção absolutamente provocadora de Lúcio.Tal transgressão expõe os interesses de Lúcio em macular não apenas um tipo de personagem ou outra, mas também toda uma moral circunscrita aos anos em que vive (e que, de um modo ou de outro, perdura ainda na contemporaneidade). Não obstante, encontramos nas novelas citadinas o escritor Lúcio Cardoso dos anos 50, que observa de forma mais acurada a derrocada espiritual sob um certo olhar cáustico, como se a danação queimasse um pecador debochado, um pecador espicaçado a soltar o seu riso demoníaco, como o riso da loucura de Rogério Palma. Se Lúcio não consegue romper de vez com seus valores mineiros, procura reagir com a provocação, o riso, o sarcasmo, o desregramento final dos que tudo podem diante da verdade eternamente insondável, como acredita Inácio nos estertores de sua vida: "Se somos fantasmas, é que procuramos estabelecer uma realidade proibida. A realidade é o segredo" ( $E$, p. 277). Se Minas é o eterno espinho fincado no coração de Lúcio Cardoso, resta-lhe expor a agonia com um riso o mais blasfemo e ultrajante possível.

\section{Referências Bibliográficas}

ATHAYDE, Tristão de. Meio século de presença literária. In: CARDOSO, Lúcio. Crônica da casa assassinada. Edição crítica coord. por Mario Carelli. São Paulo: Scipione Cultural, 1997.

ALMEIDA, Teresa de. A metrópole expressionista. Cult, São Paulo, n.14, p.5459, set. 1998.

BATAILLE, Georges. O erotismo. Trad. Antônio Carlos Viana. Porto Alegre: L\&PM, 1987.

BOSI, Alfredo. História concisa da literatura brasileira. São Paulo: Cultrix, [s/d.]

CARDOSO, Lúcio. Inácio, O enfeitiçado e Baltazar. Rio de Janeiro: Civilização Brasileira, 2002.

. O desconhecido e Mãos vazias. Rio de Janeiro: Civilização Brasileira, 2000. . Diário completo. Rio de Janeiro: José Olympio, 1970.

CARDOSO, Maria Cardoso. Vida-vida. Rio de Janeiro: José Olympio, 1973. 
CARELLI, Mario. A música do sangue. In: CARDOSO, Lúcio. Crônica da casa assassinada. Edição crítica coord. por Mario Carelli. São Paulo: Scipione Cultural, 1997.

. Crônica da casa assassinada: a consumação romanesca. In: CARDOSO, Lúcio. Crônica da casa assassinada. Edição crítica coord. por Mario Carelli. São Paulo: Scipione Cultural, 1997.

. Corcel de fogo: vida e obra de Lúcio Cardoso (1912-1968). Trad. Júlio Castañon Guimarães. Rio de Janeiro: Guanabara, 1988.

COUTINHO, Luiz Edmundo Bouças; CORRÊA, Irineu E. Jones (Org.). O labirinto finissecular e as idéias do esteta. Rio de Janeiro: 7 Letras, 2004.

FARIA, Octávio de. Lúcio Cardoso. In: CARDOSO, Lúcio. Crônica da casa assassinada. Edição crítica coord. por Mario Carelli. São Paulo: Scipione Cultural, 1997.

GENET, Jean. Diário de um ladrão. Trad. Jacqueline Laurence, Roberto Lacerda. Rio de Janeiro: Rio Gráfica, 1986.

NIETSZCHE, Friedrich. Genealogia da moral: uma polêmica. Trad. Paulo César de Souza. São Paulo: Companhia das letras, 2006.

\section{Resumo}

O presente estudo procura realizar o deslinde do artifício da provocação face às novelas urbanas do escritor mineiro Lúcio Cardoso. Em Inácio (1944) e $O$ enfeitiçado (1954) perscrutamos o percurso marginal do autor pelas cidades e os modos como sua tessitura literária ontológica atende seu ideário transgressor e provocador. A trajetória pelo submundo repleto de personagens criminosos e grotescos sustenta seu projeto pessoal de compor uma obra transgressora de forte apelo expressionista.

\section{Abstract}

This article approaches Lúcio Cardoso’s urban short novels Inácio (1944) e $O$ enfeitiçado (1954) in search of his offender and provocative ideas. The route by underground universe full of criminal and grotesque characters maintains his personal project of composing an offender work of strong expressionist appeal. 